\title{
Produção de parafasias e paralexias e sua relação com as "Dificuldades de Encontrar Palavras" (Word Finding Difficulties)
}

\author{
Thalita Cristina Souza Cruz \\ Universidade Estadual de Campinas (UNICAMP), Campinas, São Paulo, Brasil \\ thalita.souza.cruz@gmail.com \\ Diana Michaela Amaral Boccato \\ Universidade Estadual de Campinas (UNICAMP), Campinas, São Paulo, Brasil \\ diboccatoiel@gmaill.com
}

DOI: http://dx.doi.org/10.21165/el.v46i2.1800

\begin{abstract}
Resumo
Este artigo resulta de duas pesquisas abrigadas pelo Grupo de Estudos da Linguagem no Envelhecimento e nas Patologias (GELEP), desenvolvidas em nível de Doutorado e de Mestrado e visa discutir as dificuldades de encontrar palavras e sua relação com as parafasias e as paralexias. Esses fenômenos linguístico-cognitivos dão visibilidade aos processos de seleção e organização semântico-lexical e estão frequentemente relacionados às afasias. Caracterizam-se como a substituição de uma palavra pretendida por outra, em contextos orais (parafasia) e de leitura (paralexia). Pesquisas desenvolvidas no âmbito da neurolinguística enunciativo-discursiva (NOVAES-PINTO, 2009, 2014; NOVAES-PINTO; SOUZA-CRUZ, 2013; SOUZA-CRUZ, 2014) evidenciam que as trocas semântico-lexicais são recorrentes em enunciados de sujeitos com afasia fluente e não-fluente e estão relacionadas às "Dificuldade de encontrar palavras".
\end{abstract}

Palavras-chave: parafasia; paralexia; Dificuldade de Encontrar Palavras (WFD); neurolinguística.

\section{Paraphasia, paralexia and their relationship with Word Finding Difficulties}

\begin{abstract}
This paper results from two researches developed in both Doctorate and Masters Levels in Group of Studies of Language in Aging and Pathologies (GELEP). This paper's purpose is to discuss the Word Finding Difficulty and the relationship between paraphasia and paralexia. These linguisticcognitive phenomena provide visibility to the lexical-semantic selection and organization procedures and are frequently associated with aphasia. These phenomena are characterized by the replacement of the intended or target word for another, being so that paralexias occur during the reading process, while paraphasia is the oral exchange of words. Recent researches developed in the context of enunciative-discursive Neurolinguistics (NOVAES-PINTO, 2009, 2014; NOVAES-PINTO; SOUZA-CRUZ, 2013; SOUZA-CRUZ 2014) reveal that lexical-semantic paraphasias are constant in the wording of individuals with fluent aphasia or not and are related to Word Finding Difficulties.
\end{abstract}

Keywords: paraphasia; paralexia; Word Finding Difficulty (WFD); neurolinguistics. 


\section{Produção de parafasias e de paralexias: conceitos básicos para o estudo das dificuldades para encontrar palavras}

Este artigo resulta do diálogo entre duas pesquisas realizadas no âmbito do GELEP - Grupo de Estudos da Linguagem no Envelhecimento e nas Patologias (CNPq/ IEL/Unicamp) - e tem como objetivo discutir a relação entre as dificuldades de encontrar palavras e a produção de parafasias e paralexias, fenômenos neurolinguísticos intimamente relacionados com os processos de seleção e organização semântico-lexical.

A dificuldade de encontrar palavras - muitas vezes referida como WFD, do inglês Word Finding Difficulties - é um fenômeno muito comum na linguagem humana, em geral, mas que é ainda mais presente nos enunciados de sujeitos com patologias que afetam a linguagem (afasias, demências, etc.). Trata-se de situações em que não conseguimos "encontrar" a palavra desejada durante os processos de produção oral, fenômeno que pode vir ou não acompanhado da sensação de que sabemos qual é a palavra que se quer; a sensação de que estamos com a palavra "na ponta da língua" (ToT - Tip of the tongue phenomenon). Nestes casos, é muito comum que, ao tentar produzir a palavra desejada, produza-se outra relacionada a ela por algum tipo de enlace, o que caracteriza outro fenômeno: a produção de parafasias. Vale dizer que, em alguns casos, a depender da dificuldade enfrentada pelo sujeito, este desista de produzi-la ou mesmo que crie circunlóquios para "driblar" sua dificuldade de produção.

Uma das principais diferenças entre a produção de trocas em sujeitos afásicos e sujeitos não-afásicos é a autonomia para reestruturar os enunciados: enquanto o sujeito não-afásico consegue, na maior parte do tempo, reorganizar seu discurso, os sujeitos afásicos apresentam uma maior dependência de seu interlocutor para chegar ao seu “querer-dizer" (COUDRY, 1988; NOVAES-PINTO, 1999; SOUZA-CRUZ, 2013).

Tradicionalmente, as parafasias são descritas como a troca de uma palavra (ou som) que se deseja produzir - palavra/som-alvo - por outra palavra ou som efetivamente produzido oralmente. Apesar de estarem associadas às afasias fluentes, algumas pesquisas têm mostrado que elas podem estar presentes também em enunciados de sujeitos com afasias não fluentes (NOVAES-PINTO; SOUZA-CRUZ, 2012; NOVAES-PINTO, 2009; SOUZA-CRUZ, 2013, 2015). Já as paralexias caracterizam-se por serem trocas que ocorrem em contextos de leitura, relacionando-se, portanto, aos fenômenos de substituição na produção oral (parafasias) e na produção escrita (paragrafias). Apesar de também serem observáveis na linguagem cotidiana (não patológica), esses fenômenos são mais recorrentes em enunciados de sujeitos com patologias que afetam a linguagem, em especial nas afasias.

Levando em conta os contextos de avaliação, a produção de paralexias pode fornecer, com mais segurança, pistas para a compreensão dos processos semânticolexicais; ou seja, as relações entre a palavra-alvo e a palavra produzida. Isso se dá uma vez que o pesquisador sabe quais são as palavras escritas e quais foram as efetivamente produzidas pelo sujeito (BOCCATO, 2016).

Com relação aos contextos de leitura, há a possibilidade de que, na maior parte dos contextos, o funcionamento se dê a partir da compreensão mais global dos sintagmas - uma unidade em relação ao seu contexto maior. Assim, tem se que a leitura de uma palavra não é feita linearmente, letra por letra ou sílaba por sílaba, mas sim ancorada nas 
unidades precedentes e nas que a sucedem, o que permite ao sujeito selecionar a unidade por seu sentido.

Tanto as parafasias quanto as paralexias são classificadas de acordo com a natureza da relação entre a palavra-alvo e a palavra produzida, nos seguintes subtipos: i) fonético-fonológicas: quando há a troca de um som por outro (exemplo); ii) semânticas: quando há clara relação semântica entre as palavras; e iii) parafasias literais: quando não há relação semântica aparente entre as palavras. Souza-Cruz (2013) discute a imprecisão desta classificação, uma vez que as relações semânticas, apesar de em alguns casos não serem claras à primeira vista, possam ser observadas pelo contexto de produção da palavra.

Podem ocorrer também parafasias mistas, quando há tanto uma relação semântica quanto a presença de enlaces sonoros. Segundo Luria (1986), sempre há uma motivação semântica entre a palavra-alvo e a produzida, muitas vezes por enlaces afetivos, o que se confirma pelas análises qualitativas de trabalhos realizados por Novaes-Pinto (2009), Novaes-Pinto e Souza-Cruz (2012); Souza Cruz (2013) e Boccato (2016).

Com isso, a importância dos estudos qualitativos fica ainda mais evidente, já que a trajetória de uma análise qualitativa fornece ao pesquisador ferramentas que permitem a investigação dos fenômenos linguísticos como em um filme em câmera lenta. Assim, emerge a possibilidade de ocorrer uma apreensão mais elucidativa das minúcias que compõem os processos de significação, levando em conta uma perspectiva dialógica, na qual os indivíduos atuam como coautores dos processos de construção do sentido, como será visto a seguir.

\section{A abordagem neurolinguística das parafasias e das paralexias}

A Neurolinguística discursiva, abordagem que tem sido desenvolvida desde o final da década de 1980, a partir da tese de doutorado de Coudry (1986), posteriormente publicada em livro ${ }^{1}$, vem discutindo os fenômenos linguístico-cognitivos como os aqui abordados, e é respaldada pela visão sociocultural do funcionamento da linguagem e do cérebro. A área tem optado por abordagens metodológicas qualitativas, que discutem esses fenômenos a partir de contextos efetivos de comunicação.

Fenômenos linguístico-cognitivos que ocorrem nas patologias de linguagem têm se mostrado um ótimo expediente para o estudo da relação linguagem-cérebro, seja em seu estado "normal", seja em estados patológicos, ao exibir "em câmera lenta" processos subjacentes ao funcionamento linguístico que nem sempre podem ser observados na linguagem cotidiana (COUDRY, 1988 [1986]). Com o intuito de ilustrar o funcionamento desses fenômenos e sua relação com a dificuldade de encontrar palavras, apresentaremos três dados de sujeitos afásicos em que a dificuldade de encontrar palavras é observada. $\mathrm{O}$ dado 2 ilustra a dificuldade de encontrar palavras observada em um sujeito afásico. Já nos dados 1 e 3 , a dificuldade de seleção da palavra desejada leva a exemplos de produção de paralexias e parafasias.

\footnotetext{
${ }^{1}$ Diário de Narciso: discurso e afasia (1988). Para maiores informações, ver bibliografia.
} 


\section{Análise das parafasias e paralexias em enunciados de sujeitos afásicos}

Os dados aqui apresentados foram extraídos de situações reais de interação entre sujeitos afásicos e não-afásicos, em sessões realizadas no Grupo 3 do Centro de Convivência de Afásicos (CCA - IEL/UNICAMP) ${ }^{2}$.

Segundo Damico et al. (1999), ao optar por uma pesquisa qualitativa das afasias, a partir de dados autênticos e funcionais, o pesquisador tem a possibilidade de apreender tanto os sinais decorrentes de causas orgânicas, quanto os aspectos sociais e culturais do sujeito investigado, o que permite lidar de forma mais adequada com fenômenos complexos.

Essa perspectiva é compartilhada pelos defensores do paradigma microgenético, como proposto por Góes (2000), a partir dos trabalhos de Vigotski. Segundo a autora, esta visão nos permite observar:

[...] indícios, pistas, signos de aspectos relevantes de um processo em um curso; que elege episódios típicos ou atípicos (não apenas situações prototípicas) que permitem interpretar o fenômeno de interesse; que é centrada na intersubjetividade e no funcionamento enunciativo-discursivo dos sujeitos; e que se guia por uma visão indicial e interpretativoconjetural (GÓES, 2000, p. 9).

Esse paradigma, segundo Cazarotti-Pacheco (2015), tem sido utilizado em grande parte das pesquisas atuais em neurolinguística de orientação enunciativo-discursiva. Sintetizando os resultados de uma pesquisa recente da autora sobre a temática, recorremos à seguinte passagem:

A microgênese vigotskiniana é proposta com vista aos demais domínios genéticos (filogênese, ontogênese e sociogênese), que focalizam o funcionamento linguísticocognitivo dos sujeitos em todas as dimensões (biológicas, sociais e históricas). Deste modo, a Análise Microgenética possibilita demonstrar que, a partir de dados singulares, podemos inferir sobre o funcionamento da linguagem e sua relação com outros processos cognitivos, tanto na normalidade quanto nas patologias. Pois o sujeito só pode ser compreendido, nesta perspectiva, na sua relação com o signo, particularmente com a linguagem (CAZAROTTI-PACHECO, 2015, p. 21).

Para os objetivos deste trabalho, o paradigma microgenético tem se mostrado a abordagem mais adequada para orientar a análise dos dados e, consequentemente, a compreensão dos fenômenos pelos quais nos interessamos.

\section{Dado 1}

BS é um jovem afásico com 28 anos de idade, solteiro, com ensino superior incompleto em Logística. Sofreu um AVCi (Acidente Vascular Cerebral isquêmico) em outubro de 2013, passando a apresentar um quadro de afasia predominantemente motora, com a presença constante de parafasias e de paralexias literais e semânticas. Ele participa do Grupo 3 do CCA desde março de 2014.

\footnotetext{
${ }^{2}$ O Grupo III do Centro de Convivência de Afásicos (IEL/UNICAMP) é coordenado pela Profa. Dra. Rosana do Carmo Novaes Pinto há 10 anos. O CCA também é, além de um laboratório de pesquisa, um dos estágios em Linguagem do curso de Fonoaudiologia da UNICAMP.
} 
BS sempre foi um leitor voraz de livros de ficção, além de se interessar por autores brasileiros consagrados, como Machado de Assis, Lima Barreto, Carlos Drummond de Andrade, dentre outros. É guitarrista e, antes do episódio neurológico, fazia parte de uma banda de rock. No CCA, buscamos desenvolver com ele atividades musicais e de leitura, promovendo recursos alternativos de significação, para que ele possa continuar exercendo suas atividades como sujeito de linguagem, a partir de atividades que estavam inseridas em seu cotidiano antes do episódio neurológico (COUDRY, 1988 [1986]).

Uma das atividades recorrentes realizada com BS pela pesquisadora, em sessões individuais, é a leitura de diversos gêneros. Este primeiro dado é retirado de uma sessão individual em que a pesquisadora propõe a leitura do poema "O Bicho", de Manuel Bandeira, retirado do livro "Estrela da vida inteira" (2007, p. 201). Observemos, inicialmente, o poema em sua forma original:

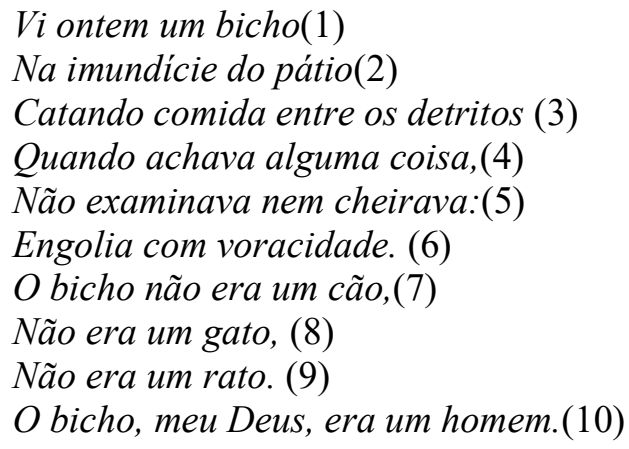

Ao ler o poema, diversas paralexias foram produzidas por BS, destacadas por nós em negrito, na versão que se segue:

Vi ontem um bicho (1)

Na imensidão do pátio(2)

Catando comida entre os estratos. (3)

Onde parece alguma coisa, (4)

Não examinava nem cheirava:(5)

Engolia com voracidade.(6)

O bicho não era um cão, (7)

Não era um gato,(8)

Não era um rato.(9)

O bicho, meu senhor, era um homem. (10)

Podemos encontrar em todas as trocas que BS realiza uma motivação semântica ou sonora - ou, em alguns casos, semântica e sonora - o que pode nos dar indícios de que essas substituições não acontecem de forma aleatória.

Um leitor que não conheça a versão original do poema e que seja submetido, primeiramente, à versão produzida por BS, muito provavelmente não estranhará o uso das palavras produzidas pelo sujeito, pois as trocas mantêm o sentido geral dos enunciados, deixando entrever as relações semânticas entre as palavras-alvo e as palavras produzidas.

Isoladamente, não há enlaces que expliquem a relação entre algumas palavrasalvo e as palavras que são produzidas em seu lugar. Eles evidenciam-se apenas no contexto mais amplo do significado do poema. Um exemplo é a troca realizada pelo sujeito, no terceiro verso, entre "detritos" e "estratos". Entretanto, tanto na versão de 
Bandeira como na versão produzida por BS, o sentido de "catar coisas entre restos" mantém-se. O mesmo pode ser observado nas trocas de "meu Deus" por "meu Senhor", no último verso do poema.

A troca de "achava" por "parece", no quarto verso, também deixa entrever uma relação semântica preservada, ambos os termos dão o sentido de se "ter impressão de algo". É importante considerar a hipótese de que tenha havido uma troca por semelhança fonológica entre "parece" e "aparece", mais uma vez mantendo o sentido do verso, que seria o de encontrar algo que está emergindo no ambiente onde se dá a ação do poema.

Além da manutenção de sentido, chama a atenção a estabilidade das categorias gramaticais, nas trocas realizadas por BS, sintetizadas no quadro abaixo:

Quadro 1

\begin{tabular}{l|l|l}
\hline Palavra-alvo & Palavra produzida & Classe gramatical \\
\hline Imundície & Imensidão & Substantivos \\
\hline Detritos & Estratos & Substantivos \\
\hline Quando & Onde & Conjunções subordinativas \\
\hline Achava & Parece & Verbos \\
\hline Meu Deus & Meu Senhor & Locuções interjetivas \\
\hline
\end{tabular}

Observando mais atentamente, é possível notar que houve também a manutenção do gênero e do número dos substantivos, o que fica claro na substituição de "detritos" por "estratos" (verso 3), ambos do gênero masculino e no plural. Também há a preservação de gênero e número na substituição da locução "Meu Deus" pela locução "Meu Senhor" (verso 10).

Nas primeiras duas paralexias produzidas (os pares "imundície-imensidão" e "detritos-estratos"), apesar da relação fonético-fonológica estar fortemente marcada (com a preservação do som inicial "im" e do som das sibilantes), podemos inferir que há uma relação que preserva tanto o sentido geral dos versos, quanto a métrica e a rima do poema original.

\section{Dado 2}

Neste segundo excerto, não observamos a produção de parafasias ou paralexias, mas é possível observar que é apenas com o auxílio da interlocutora que BS consegue chegar a seu querer-dizer.

O dado foi retirado de um experimento adaptado da bateria de Luria-Nebraska (1980), conhecido como Método do quarto excluído. Neste experimento, é apresentado ao sujeito um conjunto de quatro cartões, cada qual com uma palavra, e pede-se ao sujeito que exclua do conjunto aquele que menos se relaciona com as demais palavras.

Em nossa adaptação, além da exclusão de um dos quatro elementos apresentados, esperava-se que o sujeito pudesse justificar, em uma palavra, sua escolha. No excerto abaixo, são apresentados ao sujeito cartões com as palavras quadrado, triângulo, círculo e bola e esperava-se que o sujeito, após retirar a palavra bola, pudesse indicar um hiperônimo relacionado aos outros três elementos - no caso, o hiperônimo Geometria ou outro conceito a ele relacionado. 
Quadro 2

\begin{tabular}{|c|c|c|c|}
\hline Turno & Interlocutor & Enunciado verbal & $\begin{array}{l}\text { Observações quanto à } \\
\text { produção do enunciado }\end{array}$ \\
\hline 1 & $\mathrm{BS}$ & $\begin{array}{l}\text { Quadrado, triângulo, círculo é... } \\
\text { um...grupo de... de... Calma aí... Vou } \\
\text { explicar... Eu não sei explicar... Eu sei... }\end{array}$ & \\
\hline 2 & Its & $\begin{array}{l}\text { Você lembra o termo da escola? Você } \\
\text { quase... } \\
\text { Em que disciplina você aprende isso } \\
\text { aqui? Em que aula? }\end{array}$ & \\
\hline 3 & $\mathrm{BS}$ & & $\begin{array}{l}\text { Fica em silêncio e olha pensativo } \\
\text { para Its }\end{array}$ \\
\hline 4 & Its & $\begin{array}{l}\text { É na aula de matemática, mas tem um } \\
\text { nome específico. Você lembra esse nome } \\
\text { específico? }\end{array}$ & \\
\hline 5 & $\mathrm{BS}$ & & Faz sinal de "não" com a cabeça \\
\hline 6 & Its & Fugiu a palavra? & \\
\hline 7 & $\mathrm{BS}$ & $\begin{array}{l}\text { É... Está.... Está na ponta da língua, mas } \\
\text { não sai. }\end{array}$ & Abaixa a cabeça pensativo \\
\hline 8 & Its & Você lembra com que letra começa? & \\
\hline 9 & $\mathrm{BS}$ & & Desenha a letra $G$ na mesa \\
\hline 10 & Its & G? Ge...o... & $\mathrm{E}$ \\
\hline 11 & $\mathrm{BS}$ & Geometria? & \\
\hline 12 & Its & Isso, geometria & \\
\hline
\end{tabular}

Pelo próprio turno de BS, podemos afirmar que ele sabe de que palavra se trata, apesar de uma clara dificuldade em selecioná-la. Ele chega a afirmar, no turno 7, que está com a palavra "na ponta da língua". Its tenta auxiliar o sujeito a chegar ao seu quererdizer (BAKHTIN; VOLOSHINOV, 2006), por meio de diferentes pistas semânticas e contextuais: inicialmente, a autora tenta lembrar um nome mais geral, da disciplina escolar em que tais figuras são discutidas. No entanto, parece que a pista não causa nenhuma reação em BS. É possível que o sujeito não tenha compreendido do que a pesquisadora falava.

Mais uma vez, a interlocutora (Its) tenta retomar o contexto escolar. BS indica que não lembra a palavra e, em seguida, afirma que "está na ponta da língua, mas não sai", nos dando uma pista de que sabe de qual conceito se trata. Este conhecimento sobre a palavra é confirmado pelo sujeito ao desenhar na mesa com o dedo a letra "G". É importante frisar que só neste momento a autora tem certeza de que o sujeito e ela falam da mesma palavra e, a partir desta certeza, Its passa a dar um prompting fonológico para auxiliar BS a produzir a palavra desejada.

Fica claro, neste momento, a dificuldade de BS em encontrar palavra e a importância da relação eu-outro para que ele possa produzir a palavra desejada. É importante notar, também, que a maneira como o experimento é aplicado - não se preocupando apenas com o fato de se o sujeito produziu ou não a palavra, mas tentando compreender por que o sujeito não responde como esperado -, isto é, uma abordagem qualitativa dos experimentos realizados, é possível observar e compreender os fenômenos linguístico-cognitivos no momento em que se dão (contextos reais de uso), o que auxilia, também, na construção de recursos alternativos de significação dos sujeitos frente às suas dificuldades. 


\section{Dado 3}

Este terceiro excerto refere-se à produção de uma parafasia por outro sujeito afásico, com um perfil muito diferente do sujeito anterior - tanto com relação à sua afasia, quanto aos modos de relacionar-se com a língua.

JM é um senhor de 68 anos, casado, pai de quatro filhos, atualmente aposentado no setor metalúrgico, com ensino fundamental completo. Sofreu um AVCi em agosto de 2008 e participa do CCA desde 2009. Não relata hábitos de leitura antes do episódio neurológico, mas, segundo ele "gostava muito de falar" e de cantar, chegando a fazer parte de uma dupla sertaneja por um tempo. São comuns em sua produção linguística as dificuldades de encontrar palavras, com produção de muitas parafasias. JM relata também dificuldade de leitura, apesar de ler palavras isoladas. Em qualquer tentativa de enunciado escrito, escreve seu próprio nome, o que na literatura da área é referida por perseveração.

O episódio abaixo foi retirado de uma atividade realizada na sessão coletiva do CCA. A atividade consistia em ler um provérbio escrito no papel, completá-lo oralmente, explicar seu sentido ou dar uma explicação sobre seu sentido.

Quadro 3

\begin{tabular}{|c|c|c|c|}
\hline Turno & Enunciador & Enunciado & Observações \\
\hline 1 & JM & O que... o que... & \\
\hline 2 & Irf & Tenta ler... O que o... ó::... Os o quê? & Apontando para seus olhos \\
\hline 3 & $\mathrm{JM}$ & Olha::esse fo:: & \\
\hline 4 & Irf & O que os olhos não... & \\
\hline 5 & $\mathrm{JM}$ & Vissi...ver... & \\
\hline 6 & Irf & $\begin{array}{l}\text { Isso. O que os olhos não veem... O } \\
\text { co...coração...tenta repetir, olha aqui } \\
\text { pra minha boca }\end{array}$ & $\begin{array}{l}\text { Mostrando a palavra "coração" } \\
\text { escrita. }\end{array}$ \\
\hline 7 & Irf & Co:: & \\
\hline 8 & $\mathrm{JM}$ & Comer...não...como & \\
\hline 9 & Irf & Co:: & \\
\hline 10 & $\mathrm{JM}$ & Co:: & \\
\hline 11 & Irf & $\begin{array}{l}\text { Ra...ção. } \\
\text { O que que bate aqui, JM? }\end{array}$ & Apontando para o peito de JM \\
\hline 12 & $\mathrm{JM}$ & O coração & \\
\hline 13 & Irf & Isso mesmo. $\mathrm{O}$ coração & \\
\hline 14 & $\mathrm{JM}$ & O que? Cadê? & $\begin{array}{l}\text { Procurando a palavra escrita para ver } \\
\text { se era isso mesmo. }\end{array}$ \\
\hline 15 & Irf & $\begin{array}{l}\text { Falou... Eu perguntei o que bate aqui e } \\
\text { o senhor falou coração. Olhando na } \\
\text { minha boca foi mais difícil falar sílaba } \\
\text { por sílaba, mas a palavra inteira saiu }\end{array}$ & $\begin{array}{l}\text { Apontando novamente para o peito } \\
\text { de JM }\end{array}$ \\
\hline 16 & $\mathrm{JM}$ & Saiu. É... & \\
\hline 17 & Irf & $\begin{array}{l}\text { Então, o que os olhos não veem o } \\
\text { coração não... }\end{array}$ & \\
\hline 18 & $\mathrm{JM}$ & F...S $\ldots$ & \\
\hline 19 & $\mathrm{JM}$ & Sa...San:gue. Sempe & $\begin{array}{l}\text { Não apenas com relação ao sente, } \\
\text { mas com relação ao próprio sangue } \\
\text { que tinha dito anteriormente }\end{array}$ \\
\hline 20 & Irf & Sempe ou sente? & \\
\hline 21 & $\mathrm{JM}$ & Sente & \\
\hline 22 & Irf & $\begin{array}{l}\text { Isso, o que os olhos não veem o } \\
\text { coração não sente. Uhum...isso }\end{array}$ & \\
\hline 23 & JM & Sente & Repetindo para certificar-se \\
\hline
\end{tabular}


Neste episódio, podemos observar tanto a produção de parafasias quanto a produção de paralexias, pois, apesar de JM ler o provérbio escrito no cartão, é possível notar que, em alguns momentos, o sujeito tenta produzi-lo a partir da oralidade, sem o apoio da leitura. Mostra também a dificuldade de JM em encontrar palavras.

Além disso, pode-se observar que as trocas realizadas pelo sujeito são marcadas tanto pela relação fonético-fonológica, quanto pela relação semântica: ao tentar produzir "olhos", produz "olha". Da mesma maneira, ao tentar produzir "veem", ele produz "visse" e "ver". Em ambos os casos, observa-se que, além dos claros enlaces semânticos e sonoros entre a palavra-alvo e a palavra produzida, estas parafasias também mantêm a relação gramatical, assim como ocorre no dado 1 - acima apresentado.

Outra importante questão a ser tratada é relativa à produção de "coração" e a produção das parafasias "comer" e "como". Neste conjunto, duas questões chamam a atenção: a primeira é a própria relação entre estes três termos: uma vez dado o prompting "co", JM produz, primeiramente, "comer" e, ao tentar se autocorrigir, produz "como". Podemos pensar que, apesar de ambas as palavras não apresentarem clara relação com a palavra-alvo, esta seleção pode ter sido realizada por sua relação com prompting dado e não com relação à palavra-alvo.

A segunda questão está relacionada à mudança de contexto da produção da mesma palavra (coração). Como observado no excerto acima, JM apresenta dificuldade em produzir a palavra a partir dos promptings sonoros dado pela interlocutora. Ao perceber que este recurso não surtiria efeito, a própria pesquisadora modifica sua abordagem e questiona o sujeito sobre "o que bate aqui no peito". Ao mudar sua abordagem, o sujeito produz, sem grandes dificuldades, a palavra desejada. Ao perceber que a palavra-alvo é produzida, JM se espanta e pede para ver, no papel, se era aquela palavra que estava escrita. Além de auxiliar o sujeito na produção da palavra desejada, esta abordagem mostra, mais uma vez, a diferença que uma abordagem qualitativa, voltada para as necessidades do sujeito pode oferecer para a criação de recursos alternativos em sujeitos com patologias de linguagem.

As sessões de trabalho com os sujeitos afásicos são vídeo-filmadas e registradas em diário. As transcrições foram adaptadas do projeto NURC (Norma Urbano Culto) e as análises são de cunho microgenético, paradigma que orienta as pesquisas qualitativas realizadas pelo GELEP e que se relaciona com as abordagens histórico-culturais de Luria e Vygotsky, como veremos a seguir.

\section{Discussão teórica a partir dos dados apresentados}

Os dados aqui apresentados foram coletados a partir de excertos de situações reais de comunicação - "pois, a comunicação verbal não poderá jamais ser compreendida e explicada fora desse vínculo com a situação concreta" (BAKHTIN, 2006, p. 99) - e buscam ilustrar a relação entre a dificuldade de encontrar palavras e a produção de parafasias e paralexias. Mostram também que, ao apresentar dificuldades nos processos de seleção e produção, os sujeitos afásicos dependem mais da colaboração de seus interlocutores para chegar a seu querer-dizer, evidenciando, assim, um processo de ancoragem enunciativa (tanto no interlocutor, quanto no texto e no contexto da situação comunicativa). Segundo Rojo (1999, p. 105) a ancoragem enunciativa é: 
[...] uma operação de gestão que define a relação que o enunciador instaura com a situação de produção de seu texto ou discurso e que, neste sentido, é largamente dependente da criação que o enunciador faz de uma 'base de orientação' para a produção de seu discurso/texto. Esta criação de uma base de orientação se constitui como a definição ou instanciação dos valores dos diferentes parâmetros da interação social em curso na enunciação, ou seja, aqueles referentes às relações entre o(s) enunciador(es) e seu(s) destinatário(s), aquelas que definem o lugar social dos enunciadores e da enunciação e precisam a finalidade da atividade de linguagem.

Assim, tomando por base os dados, pode-se observar o papel do outro como constitutivo do discurso. Segundo Bakhtin (1981, p. 90), "A vida começa apenas no momento em que uma enunciação encontra outra". Para o filósofo:

[...] ter um destinatário, dirigir-se a alguém, é uma particularidade constitutiva do enunciado, sem a qual não há, e não poderia haver enunciado. As diversas formas típicas de dirigir-se a alguém e as diversas concepções típicas do destinatário são as particularidades constitutivas que determinam a diversidade dos gêneros do discurso. Dessa maneira, o destinatário é o elemento que, no contexto da comunicação social, causa no locutor a necessidade de produção de enunciados concretos (BAKHTIN, 1981, p. 90).

Toda palavra serve de expressão a um em relação ao outro. Através da palavra, definome em relação ao outro, isto é, em última análise, em relação à coletividade. A palavra é uma espécie de ponte lançada entre mim e os outros. Se ela se apoia sobre mim numa extremidade, na outra se apoia sobre o meu interlocutor. A palavra é o território comum do locutor e do interlocutor (BAKHTIN, 1981, p. 91).

Com relação à modalidade escrita, também levada em conta no presente artigo, Bakhtin (1981, p. 99) afirma que: "O livro, isto é, o ato de fala impresso, constitui igualmente um elemento da comunicação verbal. Ele é objeto de discussões ativas sob a forma de diálogo e, além disso, é feito para ser apreendido de maneira ativa".

Em sujeitos sem patologias, o outro possui papel fundamental como parceiro da comunicação. Mas, com os afásicos, o outro assume um papel ainda mais colaborativo. $\mathrm{O}$ fato de haver uma escuta ativa e sensível já se torna algo essencial para o trabalho com afásicos, pois os sujeitos com afasia estão suscetíveis a uma série de exclusões relacionadas às diversas esferas comunicativas, que se agravam pelo fato de muitos serem idosos.

No artigo "indeterminação da linguagem e afasia", a autora Rosana do Carmo Novaes-Pinto (1999, p. 165) aponta que:

[...] na linguagem dos não-afásicos os interlocutores realizam um trabalho sobre os recursos linguísticos que têm disponíveis e escolhem os mais adequados, levando em conta os pressupostos dados pela situação discursiva, fazendo ajustes para garantir uma certa "precisão" comunicativa [...]. É evidente que pode haver, pela falta de coincidência na atribuição dos sentidos destes enunciados, ambiguidades, mal entendidos, enfim, uma disputa pelo sentido. No caso dos enunciados dos sujeitos afásicos, entretanto, além de todas estas características acima citadas, há dificuldades de seleção, ou de "escolha" dos recursos disponíveis, seja por um problema no processamento ou no acesso fonológico, lexical ou de elementos sintáticos. 
Desta forma, o sujeito afásico, a partir do seu "querer dizer", fornece pistas ao interlocutor. Tais pistas podem aparecer sob várias manifestações linguísticas, e dependem do repertório linguístico, historicamente situado, de cada participante. A partir destas análises, podemos inferir algumas características do funcionamento semânticolexical e da relação entre estes fenômenos guiando-nos para uma pesquisa mais efetiva, mas, também, para uma terapia de linguagem mais voltada para os sujeitos com dificuldade de linguagem. Além disso, o estudo da linguagem em seus estados patológicos, como já apontado por Jakobson (1954) e por Coudry (1988), tem se mostrado um ótimo expediente para a discussão e compreensão do funcionamento da linguagem não patológica.

Jakobson discute a dificuldade de encontrar palavras e a produção de parafasias a partir dos eixos da linguagem, nos ajudando a compreender a natureza destes fenômenos contextualizados nos estudos linguísticos. Segundo ele, a diferença entre os tipos de afasia poderia ser explicada pelas operações em dois eixos: o eixo paradigmático, responsável pelo processo de seleção das unidades linguísticas e o eixo sintagmático, que cumpriria a função de combinar estas unidades, formando "unidades de maior complexidade" (JAKOBSON, 1954, p. 37-38).

Para Jakobson, as afasias fluentes estariam relacionadas à dificuldade de seleção das unidades linguísticas (no eixo paradigmático), levando à recorrente produção de parafasias. Os afásicos com dificuldade em selecionar as unidades linguísticas apresentariam maior dependência do contexto: ele é capaz de continuar uma conversa iniciada por outrem, mas a composição de enunciados estaria comprometida. Ainda segundo o autor, estes sujeitos se apoiariam mais na combinação das unidades - eixo sintagmático - para conseguir produzir as unidades linguísticas necessárias.

Quando a dificuldade encontrada se relaciona ao eixo sintagmático - eixo de combinação - o sujeito afásico apresentaria dificuldades em compor um enunciado, com presença de fala telegráfica. Estes casos são, geralmente, relacionados ao agramatismo por não apresentarem palavras funcionais como preposições, conjunções e cópulas.

Segundo Jakobson, a deterioração de uma dessas duas funções - de combinação ou de seleção - levaria, consequentemente, à dificuldade em outras duas importantes operações semânticas - a operação metafórica, no caso de afasias de seleção e a operação metonímica, em afasias de combinação (cf. JAKOBSON, 1954, p. 55).

É importante frisar que, para Jakobson, a relação entre o tipo de afasia e o eixo de linguagem relacionado não é estanque: não há afasia em que apenas um dos eixos esteja comprometido e o outro funcione plenamente. $\mathrm{O}$ autor entende que estes dois processos - seleção e combinação - são simultâneos, ocorrendo o que o autor chama de projeção de um eixo sobre outro: "o comprometimento em um polo leva, em algum grau, ao desarranjo no outro" (NOVAES-PINTO; SOUZA-CRUZ, 2012).

A relação feita pelo autor entre o eixo de seleção e a produção de parafasias pode auxiliar na compreensão destes fenômenos nos dados apresentados. Ela explicaria, por exemplo, a dificuldade de JM em selecionar a palavra "coração" sem outras unidades linguísticas de apoio, isto é, fora de contexto, apesar de fazê-lo sem grandes problemas quando perguntado sobre o que bate no peito. Da mesma maneira, poderia ser uma explicação para a estabilidade gramatical das paralexias produzidas por BS, como observado no primeiro dado. 
Para o estudo destes fenômenos, a partir da abordagem neurolinguística, retomamos a discussão realizada por Luria sobre a organização semântica e os enlaces multidimensionais. O autor baseia-se nos estudos de Vygotsky (1984) sobre a formação de conceitos e, assim como este, defende a linguagem como a mais complexa e mais importante entre as funções mentais superiores (cf. LURIA, 1986), de fundamental importância para o desenvolvimento de todas as demais.

Ele define a linguagem como um "complexo sistema de códigos, formado no curso da história social" (LURIA, 1986, p. 36); é ela que permite ao homem solucionar problemas, transformando o ambiente externo e tornando possível a comunicação e a transmissão de experiências entre os homens.

$\mathrm{O}$ autor defende uma abordagem do cérebro e das funções mentais superiores dentre elas a linguagem - a partir de uma concepção sócio-histórico-cultural, abordagem compatível com a abordagem discursiva da neurolinguística. Segundo o autor, os elementos externos ao cérebro, o ambiente cultural e social dos indivíduos não apenas modifica sua percepção do mundo como sua própria organização cerebral - e, consequentemente, a organização da linguagem. $\mathrm{O}$ autor incorpora, ainda, elementos intersubjetivos para a compreensão dos processos neuropsicológicos e coloca a palavra como elemento fundamental da linguagem.

Segundo Luria (1986, p. 37), é por meio da palavra que o homem designa os objetos do mundo e individualiza suas sensações. Trata-se de um conceito complexo que pode ser sintetizado na seguinte passagem do autor:

[...] a palavra não somente gera a indicação de um objeto determinado, mas, também, inevitavelmente, provoca a aparição de uma série de enlaces complementares, que incluem em sua composição elementos de palavras parecidas à primeira pela situação imediata, pela experiência anterior, etc.

No que tange à organização semântica, segundo o autor, estas relações são feitas de maneiras muito mais complexas, através de enlaces ou nós multidimensionais. Dessa forma, a relação entre elas pode se dar por enlaces sonoros e semânticos, mas elas podem estar relacionadas, igualmente, através de enlaces afetivos, pois:

[...] se cada palavra evoca um campo semântico, está unida a uma rede de associações que aparece involuntariamente, é fácil verificar que a recordação de palavras ou a denominação de objetos de nenhuma forma é a simples atualização de uma palavra. Tanto a recordação de uma palavra, como a denominação de um objeto são um processo de escolha da palavra necessária dentre todo um complexo de enlaces emergentes e ambos os atos são, por sua estrutura psíquica, muito mais complexos do que se costumava acreditar (LURIA, 1986, p. 88).

Este trecho justifica o retorno ao autor para discutirmos tanto as dificuldades de encontrar palavras quanto a produção de parafasias e paralexias. A visão de múltiplos enlaces tem auxiliado na compreensão da relação entre a palavra-alvo e a palavra produzida, seja na parafasia, seja na paralexia.

$\mathrm{O}$ autor também se refere à importância e complexidade destes fenômenos em outra passagem, ao falar, especificamente da dificuldade de nomeação de alguns sujeitos: 
[...] o campo semântico manifesta-se com toda evidência nos fenômenos amplamente conhecidos na literatura psicológica de dificuldades de recordar palavras, estados nos quais a palavra procurada encontra-se como se estivesse na ponta da língua (o conhecido tip of the tongue phenomen, descrito por Brown e Mc Neill, 1966) ou quando a palavra procurada é substituída por outra, tomada do campo semântico comum. (LURIA, 1986, p. 37)

Portanto, a palavra é uma rede potencial de enlaces multidimensionais. Enquanto nos sujeitos sem patologias os enlaces sonoros são quase sempre inibidos, em benefício de enlaces mais essenciais de natureza semântica, "como consequência da riqueza de enlaces situacionais e conceituais" (LURIA, 1986, p. 82), nas patologias, as forças inibitórias se igualam às forças de estímulo (ou são ainda mais fracas). Isso explicaria a dificuldade para o sujeito selecionar, dentre as palavras possíveis, aquela adequada ou desejada.

Segundo o autor, o desequilíbrio dessas forças, no momento de seleção da palavra desejada pode levar à produção de substituições ou mesmo da incapacidade de seleção:

A recordação da palavra necessária perde sua seletividade. No lugar da emergência seletiva exata da palavra necessária conforme um traço semântico determinado, surgem com igual probabilidade todas as palavras parecidas à procurada por traços sonoros, situacionais ou conceituais [...]. Consequentemente, podemos dizer que a palavra não é uma simples designação de objeto, ação ou qualidade. Por trás da palavra não há um significado permanente: há sempre um sistema multidimensional de enlaces. (LURIA, 1986, p. 90).

Então, a mesma dificuldade que o sujeito encontra para nomear e que pode, inclusive, levá-lo a uma anomia (não nomeação), parece estar também na base da produção de parafasias, compreendidas como as trocas - de um som por outro (neste caso, fonológicas) ou de uma palavra-alvo por uma palavra ligada à primeira por seu significado (com motivação semântica). Para Luria (1986), sempre haverá uma motivação na troca, tanto em sujeitos normais, quanto em sujeitos com alguma patologia, e isso se torna mais evidente na medida em que o compartilhamento de informações entre o sujeito afásico e seu interlocutor vai sendo realizado, tecendo, desse modo, as contexturas que perpassam e formam as enunciações.

Assim, a partir do entendimento de que as manifestações linguísticas são atravessadas pela trajetória pessoal dos sujeitos e de que o repertório linguístico é historicamente, socialmente e culturalmente determinado, fez-se necessário para o presente estudo tanto o uso de uma abordagem que leva em conta as noções de sujeito, processos dialógicos e processos de significação e interação, como faz a Neurolinguística Discursiva, quanto o uso das abordagens histórico-culturais.

\section{REFERÊNCIAS}

BAKHTIN, M.; VOLOSHINOV, V. Marxismo e Filosofia da Linguagem. São Paulo: Hucitec, 2006.

BOCCATO, D. Paralexia: compreendendo o fenômeno a partir de um estudo de caso no contexto das afasias. Projeto (Mestrado em Linguística) - Instituto de Estudos da Linguagem, Universidade Estadual de Campinas, Campinas, 2016 (Em andamento). 
CAZAROTTI-PACHECO, M. Contribuições da análise microgenética às pesquisas em neurolinguística. Revista de Estudos Linguísticos, v. 45, n. 2, p. 582-594, 2016.

COUDRY, M. I. H. Diário de Narciso: discurso e afasia. São Paulo: Editora Martins Fontes, 1988.

DAMICO, J. et al. Qualitative methods in aphasia research: basic issues. Aphasiology, v. 13, n. 9-11, p. 651-665, 1999.

GÓES, M. C. R. A abordagem microgenética na matriz histórico-cultural: Uma perspectiva para o estudo da constituição da subjetividade. Caderno Cedes, v. 50, p. 925,2000 .

JAKOBSON, R. Linguística e Comunicação. São Paulo: Editora Cultrix, 1954.

LURIA, A. R. Pensamento e linguagem: as últimas conferências de Luria. São Paulo: Artes Médicas, 1986.

NOVAES-PINTO, R. C. Indeterminação da linguagem e afasia. Estudos Linguísticos, São Paulo, v. 28, p. 162-167, 1999.

CONGRESSO INTERNACIONAL DA ABRALIN, 6, 2009, João Pessoa. Anais... João Pessoa: UFPB, 2009.

NOVAES-PINTO, R. C.; SOUZA-CRUZ, T. Funcionamento semântico-lexical: discussão crítica com base em dados de situações dialógicas com sujeitos afásicos. Revista de Estudos Linguísticos, v. 41, n. 2, p. 708-722, 2012.

ROJO, R. H. R. Elaborando uma progressão didática de gêneros: aspectos lingüísticoenunciativos envolvidos no agrupamento de gêneros "relatar". In: Intercâmbio, v. VIII, p. 101-118, 1999.

SOUZA-CRUZ, T. Em briga de marido e mulher ninguém mete... o garfo: Estudo neurolinguístico da produção de parafasias semânticas em sujeitos afásicos. 2013. $100 \mathrm{f}$. Dissertação (Mestrado em Linguística) - Instituto de Estudos da Linguagem, Universidade Estadual de Campinas, Campinas, 2013.

SOUZA-CRUZ, T. A produção de parafasias em sujeitos com afasias fluentes e não fluentes. Estudos Linguísticos, v. 44, n. 2, p. 853-867, 2015.

Recebido em: 06/02/2017

Aprovado em: 27/03/2017 